\title{
Níveis de metionina + cistina para características de desempenho e de carcaça em codornas de corte EV2
}

\author{
[Methionine + cystine requirements for performance and carcass traits of EV2 meat-type quails] \\ G.S.S. Corrêe $a^{1,4}$, M.A. Silva, ${ }^{2,4}$, A.B. Corrêa ${ }^{3}$, D.O. Fontes ${ }^{2,4}$, G.G. Santos ${ }^{3}$, \\ L.S. Freitas ${ }^{3}$, R.R. Wenceslau ${ }^{3}$ \\ ${ }^{1}$ Pós-doutoranda - EV-UFMG - Belo Horizonte, MG \\ ${ }^{2}$ Escola de Veterinária - UFMG \\ Caixa Postal 567 \\ 30123-970 - Belo Horizonte, MG \\ ${ }^{3}$ Aluno de pós-graduação - EV-UFMG - Belo Horizonte, MG \\ ${ }^{4}$ Bolsista do CNPq
}

\begin{abstract}
RESUMO
Estudou-se a exigência de metionina + cistina para codornas de corte em crescimento. O delineamento experimental foi inteiramente ao acaso, com cinco repetições de 13 codornas por unidade experimental. Os tratamentos consistiram de seis níveis de metionina + cistina - 0,73;0,79;0,85;0,91;0,97 e 1,03\%. Foram registrados peso corporal $(\mathrm{g})$, ganho de peso $(\mathrm{g})$, consumo de ração $(\mathrm{g})$ e conversão alimentar $(\mathrm{g} / \mathrm{g})$ em cada fase de crescimento $\left(7^{\circ}\right.$ ao $21^{\circ}$ dia) e total $\left(7^{\circ}\right.$ ao $42^{\circ}$ dia de idade). No $42^{\circ}$ dia, quatro codornas de cada unidade experimental (dois machos e duas fêmeas), após jejum de sólidos de oito horas, foram amostradas, pesadas e abatidas para avaliação dos pesos e rendimentos de carcaças em relação ao peso vivo e rendimentos dos cortes (peito e coxas) e das vísceras comestíveis (fígado, moela e coração) e gordura abdominal em relação ao peso da carcaça eviscerada (sem pés e sem cabeça). Os níveis de metionina + cistina da dieta influíram de forma quadrática no peso ao $21^{\circ}$ dia e no ganho de peso do $7^{\circ}$ ao $21^{\circ}$ dia de idade das codornas, com máximo desempenho em $0,95 \%$ de metionina + cistina. A conversão alimentar apresentou comportamento linear decrescente significativo. Houve efeito linear dos níveis dos aminoácidos metionina + cistina sobre o peso ao $42^{\circ}$ dia, ganho de peso e consumo de alimento do $7^{\circ}$ ao $42^{\circ}$ dia de idade. Não houve efeito dos níveis de metionina + cistina da dieta sobre o peso vivo, peso e rendimento de carcaça, peito, coxa, gordura abdominal, fígado, moela e coração. Maiores peso corporal, carcaça eviscerada, coxa, peito, gordura abdominal, moela, peso e rendimento de fígado foram observados nas fêmeas, enquanto os machos apresentaram maior rendimento de carcaça eviscerada. Maior ganho de peso foi observado em codornas de corte EV2 em crescimento alimentadas com dietas que continham $0,95 \%$ de metionina + cistina na fase inicial $\left(7^{\circ}\right.$ ao $21^{\circ}$ dia $)$ e $1,03 \%$ na fase total $\left(7^{\circ}\right.$ ao $42^{\circ}$ dia de idade), o que corresponde às relações de metionina + cistina: lisina de 0,73 e $0,79 \%$, e ao consumo de metionina + cistina diário de $0,134 \mathrm{~g}$ e $0,234 \mathrm{~g} /$ codorna, respectivamente.
\end{abstract}

Palavras chave: codorna, exigência nutricional, aminoácido, desempenho, metionina + cistina, característica de carcaça

\section{ABSTRACT}

Methionine + cystine requirements for meat type quails during the growing phase were evaluated in a completely randomized experimental design with five levels of methionione + cystine $(.73, .79, .85, .91, .97$, and $1.03 \%)$, and five replicates of 13 quails per experimental unit. Body weight ( $g$ ), weight gain ( $g$ ), feed intake $(\mathrm{g})$, and feed: weight gain ratio were recorded for each experimental period (from seven to 21 days and seven to 42 days of age). At 42 days of age, four quails (two males and two females) were randomly sampled from each experimental unit, slaughtered after a jejunum of eight hours to evaluate weights and yields of carcass relative to live body weight and yields of main cuts (breast and thigh), edible giblets (liver, gizzard, and heart) and abdominal fat relative to carcass weight (without foot and head). Methionine + cystine levels showed quadratic effects on body weight and weight gain at 21 days of age, with estimated maximum performances for

Recebido em 5 de outubro de 2009

Aceito em 2 de agosto de 2010

* Autor para correspondência (corresponding author)

E-mail: martinho@vet.ufmg.br 
quails fed $.95 \%$ methionine + cystine level, while feed:weight gain ratio decreased with the increasing level of these amino acids. Significant and linear effects of methionine + cystine on body weight were observed at 42 days of age on weight; and on weight gain and feed intake from seven to 42 days of age. No significant effects of methionine + cystine were observed for live body weight, weights and yields of breast, thigh, abdominal fat, liver, gizzard, and heart. Higher body weight, eviscerated carcass, thigh, breast, abdominal fat, gizzard, and liver weight and yield were observed for females, while males showed higher eviscerated carcass weight. The highest weight gains were observed for EV2 quails fed $.95 \%$ methionine + cystine from $7^{\text {th }}$ to $21^{\text {st }}$ days of age and from $7^{\text {th }}$ to $42^{\text {nd }}$ days of age corresponding to a methionine + cystine: lysine ratio of $.73 \%$ and $.79 \%$ and to a daily methionine + cystine intake of .134 and $.234 \mathrm{~g} /$ quail, respectively.

Keywords: quail, nutritional requirement, amino acid, performance, total methionine + cystine, carcass yield

\section{INTRODUÇÃO}

$\mathrm{Na}$ elaboração de programa nutricional para codornas de corte, o nutricionista baseia-se nas recomendações do NRC (Nutrient..., 1994) que são elaboradas para atender as exigências de codornas japonesas com peso corporal menor que o das codornas de corte. Essas exigências são baseadas em resultados de experimentos realizados há mais de 15 anos e em codornas com potencial genético diferente das criadas atualmente (Corrêa et al., 2007a).

Os aminoácidos da dieta são usados pelas codornas para inúmeras funções, tais como constituintes primários dos tecidos e de proteção, pele, penas, matriz óssea, ligamentos e tecidos dos órgãos e músculos. Assim, os aminoácidos e pequenos peptídeos resultantes dos processos de digestão-absorção dos alimentos podem ser utilizados para uma variedade de funções metabólicas e como precursores de inúmeros constituintes corporais não-proteicos. Quando o nível de proteína (aminoácidos) da ração é inadequado, há redução, cessa o crescimento ou a produtividade do animal, e há a mobilização da proteína dos tecidos menos vitais para manutenção do metabolismo vital.

Entretanto, a exigência em proteína e aminoácidos varia consideravelmente de acordo com o estádio de produção da ave, tamanho corporal, taxa de crescimento e, ainda, diferenças na exigência em aminoácidos podem ocorrer por diferenças na eficiência de digestão, absorção dos nutrientes e metabolismo dos nutrientes absorvidos.

Os aumentos na produção de aminoácidos sintéticos têm possibilitado a redução dos níveis de proteína da dieta quando associada à suplementação de aminoácidos. Jensen (1987), ao trabalhar com a suplementação de aminoácidos em substituição à proteína, verificou queda linear no ganho de peso e aumento linear na conversão alimentar e gordura abdominal.

Baker e Han (1994), ao estudarem o perfil ideal de aminoácidos para pintos durante as três primeiras semanas de vida, encontraram valores de exigência de $72 \%$ para metionina + cistina, tendo como aminoácido de referência a lisina (100\%).

Segundo Schutte e Pack (1995), estudos sobre a influência de aminoácidos individuais sobre a composição de carcaça ainda são limitados, principalmente na fase final de criação. Existem poucos resultados para descrever e quantificar as relações entre o conteúdo de aminoácidos dietéticos e características de qualidade de carcaça, como, por exemplo, a percentagem de peito. Esta limitação das informações pode ser atribuída ao custo alto destes experimentos, e à grande variabilidade que existe entre as carcaças e ao pequeno número de observações comumente utilizadas nos estudos de rendimento de carcaças.

Alguns resultados também mostram que frangos de corte aumentam o consumo de alimento, em função da quantidade de metionina da dieta, o que pode resultar em aumento da deposição de gordura abdominal (Moran, 1994).

Portanto, este trabalho visou estudar o efeito de diferentes níveis de metionina + cistina total sobre o desempenho, rendimento e composição corporal de codornas de corte, do grupo genético EV2, durante o período de crescimento. 


\section{MATERIAL E MÉTODOS}

Foram utilizadas 390 codornas de corte de ambos os sexos, do $7^{\circ}$ ao $42^{\circ}$ dia de idade, com peso médio inicial de $25,05 \mathrm{~g}$, as quais foram alojadas em baterias de arame galvanizado com dimensões de $0,82 \mathrm{~m}$ de largura x $0,41 \mathrm{~m}$ de profundidade $\mathrm{x} 0,27 \mathrm{~cm}$ de altura por unidade experimental, equipadas com bebedouro copo e comedouro tipo calha.

O aquecimento das codornas na fase inicial foi realizado com lâmpadas incandescentes de 100 Watts na primeira semana e de 60 Watts na segunda semana, e o programa de luz adotado, durante a fase experimental, foi de 24 horas.

O delineamento experimental foi inteiramente ao acaso com seis níveis de metionina $(0,73 ; 0,79$; $0,85 ; 0,91 ; 0,97$ e $1,03 \%)$ e cinco repetições de 13 aves por unidade experimental.

As aves foram alimentadas com a dieta basal (Tab. 1), formulada à base de milho e farelo de soja, contendo $23,89 \%$ de proteína bruta $(\mathrm{PB})$ e $2900 \mathrm{kcal}$ de EM/kg de dieta, e $0,73 \%$ de metionina + cistina. A dieta basal foi suplementada com cinco níveis de DL-metionina (99\%), em substituição ao amido de milho, o que corresponde aos níveis de 0,73 (dieta basal sem suplementação); 0,$79 ; 0,85 ; 0,91 ; 0,97$ e $1,03 \%$ de metionina + cistina total, permanecendo as dietas isocalóricas e isoproteicas. As dietas foram fornecidas à vontade e os bebedouros limpos diariamente.

Para avaliação do desempenho, o peso corporal (g), ganho de peso $(\mathrm{g})$, consumo de ração $(\mathrm{g})$ e conversão alimentar (g de ração/g de peso) do $7^{\circ}$ ao $21^{\circ}$ dia e do $7^{\circ}$ ao $42^{\circ}$ dia de idade foram registrados para cada unidade experimental.

Para controle do consumo alimentar, as rações de cada repetição, em cada tratamento, foram acondicionadas em sacos plásticos de um quilograma e estes, por sua vez, acondicionados em baldes plásticos identificados. Ao final de cada período, as sobras de ração do comedouro de cada unidade experimental foram pesadas e, por diferença entre ração fornecida e as sobras, determinou-se o consumo por período (g/ave). A conversão alimentar por ave foi calculada dividindo-se o consumo de ração/ave pelo ganho de peso/ave de cada unidade experimental e em cada período do experimento.

Para avaliação das características de carcaça, no $42^{\circ}$ dia, quatro codornas de cada unidade experimental (dois machos e duas fêmeas), após jejum de sólidos de oito horas foram amostradas, pesadas, abatidas, depenadas, evisceradas e avaliadas quanto aos pesos e rendimentos de carcaças em relação ao peso vivo e rendimentos dos cortes (peito e coxas), vísceras comestíveis (fígado, moela e coração) e gordura abdominal em relação ao peso da carcaça eviscerada (sem pés e sem cabeça). Para análise destas variáveis, ao modelo estatístico anteriormente estabelecido incluíram-se o efeito de sexo e de sua interação com os níveis de metionina + cistina da dieta. Foram estudados o peso vivo (PV), os pesos e rendimentos de carcaça, peito, coxas, vísceras comestíveis e gordura abdominal.

As análises dos dados foram realizadas por meio do programa SAEG (Sistema..., 2007). Os efeitos dos níveis de metionina + cistina foram calculados por análise de regressão, ao se desdobrarem os graus de liberdade dos fatores em seus componentes lineares e quadráticos para escolha do modelo de regressão que melhor descrevesse as observações.

\section{RESULTADOS E DISCUSSÃO}

Os níveis de metionina + cistina da dieta influíram de forma quadrática no peso final no $21^{\circ}$ dia e no ganho de peso do $7^{\circ}$ ao $21^{\circ}$ dia de idade das codornas (Tab. 2), de acordo com as seguintes equações de regressão $\hat{Y}_{i}=-163,47+$ $605,32 \mathrm{X}_{\mathrm{i}}-318,02 \mathrm{X}_{\mathrm{i}}^{2}$ (Fig. 1) e $\hat{Y}_{i}=-195,86+$ $619,91 X_{i}-326,50 X_{i}^{2}$ (Fig. 2), com nível estimado de $0,95 \%$ de metionina + cistina na dieta para máximo desempenho de codornas durante a fase inicial de criação. Resultados semelhantes foram encontrados por Corrêa et al. (2006) que estimaram em $0,95 \%$ o nível de metionina + cistina para máximos peso e ganho de peso de codornas de corte do $7^{\circ}$ ao $21^{\circ}$ dia de idade. O mesmo comportamento também foi observado por Corrêa et al. (2007c) em estudo sobre o efeito de níveis de proteína bruta para codornas de corte em crescimento. 
Tabela 1. Composição percentual e calculada da dieta basal

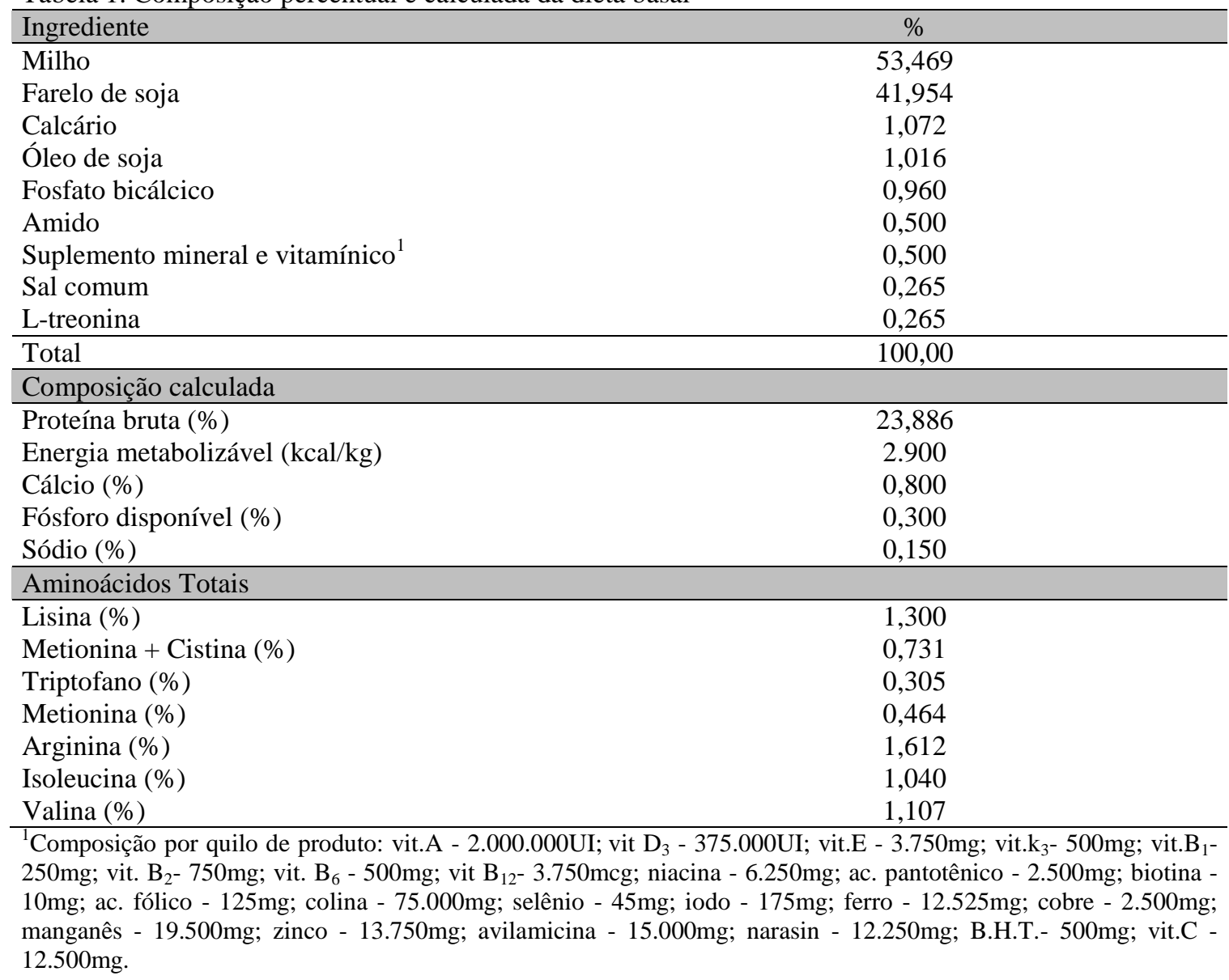

Tabela 2. Efeito do nível de metionina + cistina total sobre o peso final, ganho de peso, consumo de ração e conversão alimentar das codornas de corte $7^{\circ}$ ao $21^{\circ}$ dia de idade

\begin{tabular}{|c|c|c|c|c|}
\hline Nível de metionina & $\begin{array}{l}\text { Peso final } \\
(\mathrm{g})\end{array}$ & $\begin{array}{l}\text { Ganho de peso } \\
(\mathrm{g})\end{array}$ & $\begin{array}{c}\text { Consumo de ração } \\
(\mathrm{g})\end{array}$ & $\begin{array}{c}\text { Conversão alimentar } \\
(\mathrm{g} / \mathrm{g})\end{array}$ \\
\hline 0,73 & 108,15 & 81,80 & 186,20 & 2,28 \\
\hline 0,79 & 118,80 & 92,75 & 191,56 & 2,07 \\
\hline 0,85 & 117,99 & 91,92 & 203,87 & 2,22 \\
\hline 0,91 & 126,70 & 100,41 & 198,18 & 1,98 \\
\hline 0,97 & 122,89 & 96,64 & 199,17 & 2,06 \\
\hline 1,03 & 123,11 & 96,78 & 196,17 & 2,03 \\
\hline $\mathrm{CV}$ & 2,93 & 3,56 & 7,98 & 8,46 \\
\hline Significância & $*$ & $*$ & $\mathrm{~ns}$ & $*$ \\
\hline & \multicolumn{3}{|c|}{ Equação de regressão } & $\begin{array}{c}\text { Nível de melhor } \\
\text { desempenho }\end{array}$ \\
\hline Peso final & \multicolumn{3}{|c|}{$\hat{Y}_{i}=-163,47+605,32 \mathrm{X}_{\mathrm{i}}-318,02 \mathrm{X}_{\mathrm{i}}^{2}\left(\mathrm{R}^{2}=0,87\right)$} & 0,95 \\
\hline Ganho de peso & \multicolumn{3}{|c|}{$\hat{Y}_{i}=-195,86+619,91 \mathrm{X}_{\mathrm{i}}-326,50 \mathrm{X}_{\mathrm{i}}^{2}\left(\mathrm{R}^{2}=0,87\right)$} & 0,95 \\
\hline Conversão alimentar & \multicolumn{3}{|c|}{$\hat{Y}_{i}=2,73-0,71 \mathrm{X}_{\mathrm{i}}\left(\mathrm{R}^{2}=0,47\right)$} & 1,03 \\
\hline
\end{tabular}

*=significativo $(\mathrm{P}<0,05)$; ns=não significativo. 


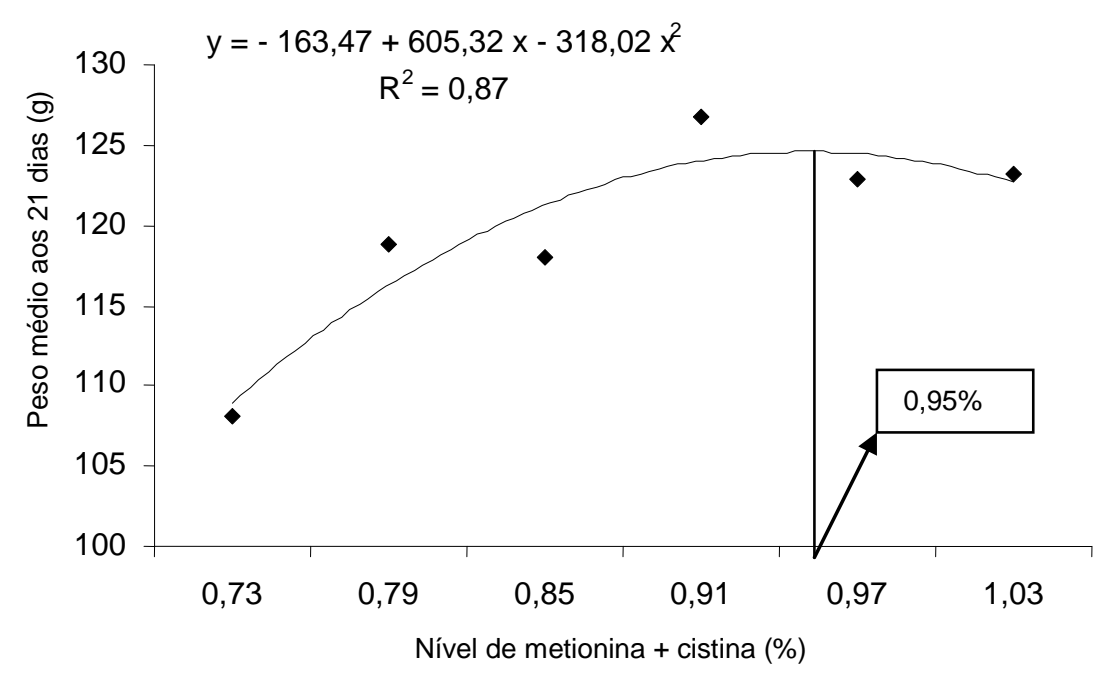

Figura 1. Regressão do peso no $21^{\circ}$ dia de idade de codornas de corte EV2 em relação ao nível de metionina + cistina da dieta.

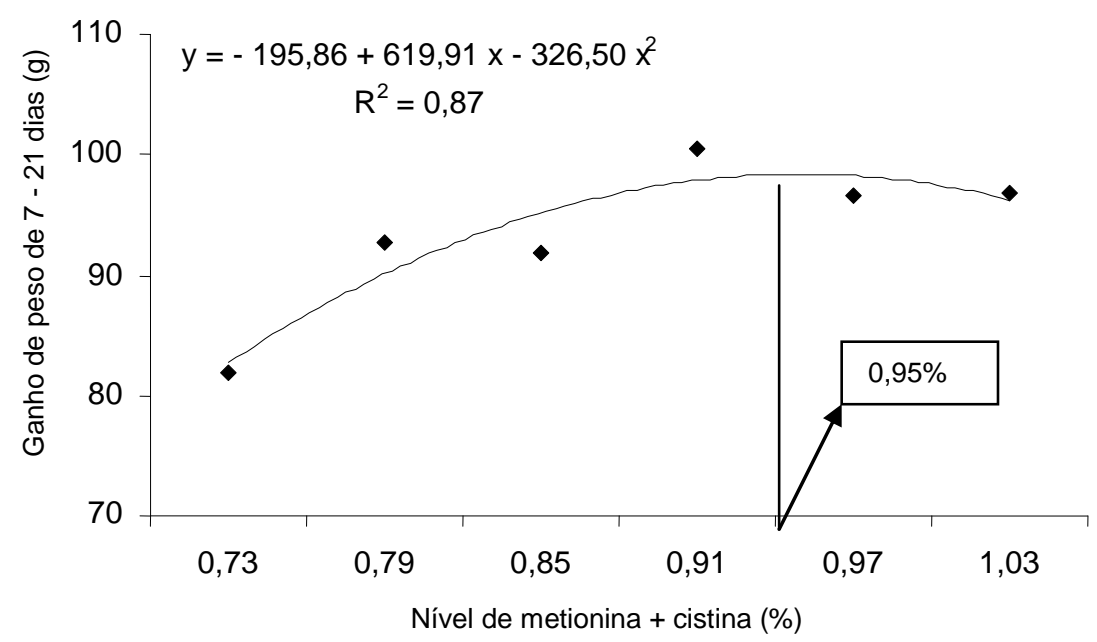

Figura 2. Regressão do ganho de peso do $7^{\circ}$ ao $21^{\circ}$ dia de idade de codornas de corte EV2 em relação ao nível de metionina + cistina da dieta.

A conversão alimentar (Tab. 2) apresentou comportamento linear decrescente significativo, com equação estimada em $\hat{Y}_{i}=2,73-0,71 \mathrm{X}_{\mathrm{i}}$, ou seja, à medida que se aumentaram os níveis de metionina + cistina, houve melhora na conversão alimentar. O consumo alimentar não foi influenciado pelos níveis de metionina + cistina da dieta.
Os resultados deste experimento são semelhantes aos observados por Torres et al. (2005a), que também não encontraram efeito dos níveis de metionina + cistina sobre o consumo e conversão alimentar das codornas de corte durante a fase inicial de criação. Contudo, Murakami et al. (1994) e Stringhini et al. (1995) não observaram efeito significativo dos níveis de aminoácidos sulfurosos sobre o consumo alimentar de codornas japonesas. 
Houve efeito linear dos níveis de metionina + cistina da dieta sobre o peso no $42^{\circ}$ dia, ganho de peso e consumo de alimento do $7^{\circ}$ ao $42^{\circ}$ dia de idade (Tab. 3), com equações de regressão estimadas em $\hat{Y}_{i}=212,81+38,46 \mathrm{X}_{\mathrm{i}}, \quad \hat{Y}_{i}=$ $186,89+38,11 \mathrm{X}_{\mathrm{i}}$ e $\hat{Y}_{i}=623,52+167,06 \mathrm{X}_{\mathrm{i}}$. Portanto, as dietas únicas para o período total de criação devem ser formuladas com níveis altos de metionina + cistina para máximo ganho de peso. Estes resultados são semelhantes aos encontrados por Pinto et al. (2003) que também verificaram efeito linear positivo dos níveis de metionina + cistina digestível sobre o peso no $42^{\circ}$ dia e o ganho de peso de $7^{\circ}$ ao $42^{\circ}$ dia de idade, para codornas japonesas. Corrêa et al. (2005; 2007b) observaram diminuição da exigência de proteína com o aumento da idade, e os autores concluem que isto ocorreu em função do menor ganho de peso com o aumento da idade da codorna.

Tabela 3. Efeito do nível de metionina + cistina total sobre o peso final, ganho de peso, consumo de ração e conversão alimentar das codornas de corte do $7^{\circ}$ ao $42^{\circ}$ dia de idade

\begin{tabular}{|c|c|c|c|c|}
\hline $\begin{array}{l}\text { Nível de } \\
\text { metionina }\end{array}$ & $\begin{array}{l}\text { Peso final } \\
\quad(\mathrm{g})\end{array}$ & $\begin{array}{l}\text { Ganho de peso } \\
\text { (g) }\end{array}$ & $\begin{array}{l}\text { Consumo de } \\
\text { ração } \\
(\mathrm{g})\end{array}$ & $\begin{array}{l}\text { Conversão } \\
\text { alimentar } \\
(\mathrm{g} / \mathrm{g})\end{array}$ \\
\hline 0,73 & 240,02 & 213,67 & 736,48 & 3,45 \\
\hline 0,79 & 243,68 & 217,63 & 768,98 & 3,54 \\
\hline 0,85 & 242,19 & 216,12 & 767,47 & 3,55 \\
\hline 0,91 & 253,93 & 227,65 & 777,12 & 3,41 \\
\hline 0,97 & 250,18 & 223,93 & 767,69 & 3,43 \\
\hline 1,03 & 249,93 & 223,60 & 805,49 & 3,60 \\
\hline $\mathrm{CV}$ & 2,69 & 2,94 & 3,38 & 3,50 \\
\hline Significância & $*$ & $*$ & $*$ & $\mathrm{~ns}$ \\
\hline & \multicolumn{2}{|c|}{ Equação de Regressão } & \multicolumn{2}{|c|}{ Nível de melhor desempenho } \\
\hline Peso final & \multicolumn{2}{|c|}{$\hat{Y}_{i}=212,81+38,46 \mathrm{X}_{\mathrm{i}}\left(\mathrm{R}^{2}=0,63\right)$} & \multicolumn{2}{|c|}{1,03} \\
\hline Ganho de peso & \multicolumn{2}{|c|}{$\hat{Y}_{i}=186,89+38,11 \mathrm{X}_{\mathrm{i}}\left(\mathrm{R}^{2}=0,63\right)$} & \multicolumn{2}{|c|}{1,03} \\
\hline $\begin{array}{l}\text { Consumo } \\
\text { alimentar }\end{array}$ & \multicolumn{2}{|c|}{$\hat{Y}_{i}=623,52+167,06 \mathrm{X}_{\mathrm{i}}\left(\mathrm{R}^{2}=0,72\right)$} & \multicolumn{2}{|c|}{0,73} \\
\hline
\end{tabular}

*=significativo $(\mathrm{p}<0,05) ; \mathrm{ns}=$ não significativo.

Corrêa et al. (2006) não observaram diferenças significativas para a conversão alimentar em relação à exigência de metionina + cistina, do $7^{\circ}$ ao $42^{\circ}$ dia de idade de codornas de corte.

Não houve efeito dos níveis de metionina + cistina da dieta sobre o peso vivo antes do abate, peso e rendimento de carcaça, peito, coxa, gordura abdominal, fígado, moela e coração. Estes resultados indicam que nem mesmo o nível mais alto de metionina + cistina, usado neste experimento $(1,03 \%)$, foi suficiente para alterar o comportamento dessas variáveis, o que também foi observado por Barbosa et al. (2001) que não observaram efeito dos níveis crescentes de metionina + cistina sobre as características de carcaça de frangos de corte.

Maiores peso corporal, carcaça eviscerada, coxas, peito, gordura abdominal, moela, peso e rendimento de fígado foram observados nas fêmeas (Tab. 4), enquanto os machos apresentaram maior rendimento de carcaça eviscerada.

O maior desempenho das fêmeas é atribuído ao acentuado dimorfismo sexual, decorrente dos maiores desenvolvimentos do aparelho reprodutivo e dos órgãos correlacionados, que ocorrem antes do início da produção de ovos $\left(42^{\circ}\right.$ dia de idade). 


\section{Corrêa et al.}

Tabela 4. Características de carcaça de codornas de corte alimentadas com diferentes níveis de metionina + cistina

\begin{tabular}{|c|c|c|c|c|c|c|c|c|}
\hline \multirow{2}{*}{ Variável } & \multirow{2}{*}{ Sexo } & \multicolumn{6}{|c|}{ Nível de metionina (\%) } & \multirow[b]{2}{*}{ Média } \\
\hline & & 0,73 & 0,79 & 0,85 & 0,91 & 0,97 & 1,03 & \\
\hline \multirow{2}{*}{ Peso vivo (g) } & $\mathrm{M}$ & 222,20 & 216,20 & 211,60 & 214,40 & 219,60 & 210,40 & $215,73 \mathrm{~B}$ \\
\hline & $\mathrm{F}$ & 250,20 & 255,40 & 251,60 & 248,80 & 235,40 & 229,80 & $245,20 \mathrm{~A}$ \\
\hline \multirow{2}{*}{ Peso da carcaça (g) } & $\mathrm{M}$ & 152,80 & 157,80 & 157,00 & 159,20 & 161,80 & 153,00 & $156,93 \mathrm{~B}$ \\
\hline & $\mathrm{F}$ & 166,80 & 179,40 & 177,20 & 169,40 & 169,20 & 153,80 & $169,30 \mathrm{~A}$ \\
\hline \multirow{2}{*}{$\begin{array}{l}\text { Rendimento de carcaça } \\
(\%)\end{array}$} & $\mathrm{M}$ & 68,96 & 72,94 & 74,27 & 74,23 & 73,64 & 72,49 & $72,75 \mathrm{~A}$ \\
\hline & $\mathrm{F}$ & 67,14 & 70,04 & 70,49 & 67,99 & 71,88 & 67,40 & $69,16 \mathrm{~B}$ \\
\hline \multirow{2}{*}{ Peso da coxa (g) } & $\mathrm{M}$ & 39,00 & 39,80 & 40,80 & 38,20 & 39,40 & 39,20 & $39,40 \mathrm{~B}$ \\
\hline & $\mathrm{F}$ & 44,60 & 43,20 & 45,00 & 42,20 & 41,00 & 39,80 & $42,63 \mathrm{~A}$ \\
\hline \multirow{2}{*}{ Rendimento da coxa (\%) } & $\mathrm{M}$ & 25,73 & 25,16 & 26,20 & 24,08 & 24,35 & 26,04 & $25,26 \mathrm{~A}$ \\
\hline & $\mathrm{F}$ & 26,84 & 24,20 & 25,55 & 25,07 & 24,23 & 25,70 & $25,27 \mathrm{~A}$ \\
\hline \multirow{2}{*}{ Peso do peito (g) } & $\mathrm{M}$ & 61,80 & 63,40 & 61,80 & 62,40 & 65,60 & 61,40 & $62,73 \mathrm{~B}$ \\
\hline & $\mathrm{F}$ & 68,60 & 68,80 & 75,20 & 73,00 & 66,20 & 61,40 & $68,87 \mathrm{~A}$ \\
\hline \multirow{2}{*}{ Rendimento do peito (\%) } & $\mathrm{M}$ & 40,50 & 40,21 & 39,26 & 39,24 & 40,51 & 40,45 & $40,03 \mathrm{~A}$ \\
\hline & $\mathrm{F}$ & 41,34 & 38,24 & 42,41 & 42,95 & 39,23 & 39,88 & $40,68 \mathrm{~A}$ \\
\hline \multirow{2}{*}{$\begin{array}{l}\text { Peso da gordura abdominal } \\
(\mathrm{g})\end{array}$} & $\mathrm{M}$ & 2,00 & 2,40 & 2,64 & 2,48 & 2,40 & 2,60 & $2,42 \mathrm{~A}$ \\
\hline & $\mathrm{F}$ & 3,46 & 3,32 & 3,06 & 2,60 & 2,56 & 3,32 & $3,05 \mathrm{~B}$ \\
\hline \multirow{2}{*}{$\begin{array}{l}\text { Rendimento da gordura } \\
\text { abdominal }(\%)\end{array}$} & $\mathrm{M}$ & 1,30 & 1,51 & 1,62 & 1,56 & 1,49 & 1,57 & $1,51 \mathrm{~A}$ \\
\hline & $\mathrm{F}$ & 2,06 & 1,88 & 1,76 & 1,49 & 1,49 & 2,18 & $1,81 \mathrm{~A}$ \\
\hline \multirow{2}{*}{ Peso do fígado (g) } & $\mathrm{M}$ & 4,06 & 4,00 & 4,00 & 4,20 & 3,70 & 3,84 & $3,97 \mathrm{~B}$ \\
\hline & $\mathrm{F}$ & 6,20 & 6,34 & 5,92 & 6,52 & 6,06 & 5,20 & $6,04 \mathrm{~A}$ \\
\hline \multirow{2}{*}{ Rendimento do fígado (\%) } & $\mathrm{M}$ & 2,64 & 2,54 & 2,56 & 2,63 & 2,27 & 2,54 & $2,53 \mathrm{~B}$ \\
\hline & $\mathrm{F}$ & 3,70 & 3,64 & 3,38 & 3,94 & 3,59 & 3,39 & $3,61 \mathrm{~A}$ \\
\hline \multirow{2}{*}{ Peso da moela $(\mathrm{g})$} & M & 4,04 & 4,60 & 4,16 & 4,30 & 3,74 & 4,08 & $4,15 \mathrm{~B}$ \\
\hline & $\mathrm{F}$ & 4,90 & 4,26 & 4,86 & 4,58 & 4,78 & 4,66 & $4,67 \mathrm{~A}$ \\
\hline \multirow{2}{*}{ Rendimento da moela (\%) } & $\mathrm{M}$ & 2,64 & 2,91 & 2,65 & 2,69 & 2,31 & 2,68 & $2,65 \mathrm{~A}$ \\
\hline & $\mathrm{F}$ & 2,94 & 2,40 & 2,78 & 2,71 & 2,81 & 3,03 & $2,78 \mathrm{~A}$ \\
\hline \multirow{2}{*}{ Peso do coração $(\mathrm{g})$} & $\mathrm{M}$ & 2,34 & 2,14 & 2,32 & 2,28 & 2,22 & 2,34 & $2,27 \mathrm{~A}$ \\
\hline & $\mathrm{F}$ & 2,58 & 2,56 & 2,42 & 2,34 & 2,34 & 2,08 & $2,39 \mathrm{~A}$ \\
\hline \multirow{2}{*}{$\begin{array}{l}\text { Rendimento do coração } \\
(\%)\end{array}$} & $\mathrm{M}$ & 1,54 & 1,36 & 1,47 & 1,44 & 1,37 & 1,53 & $1,45 \mathrm{~A}$ \\
\hline & $\mathrm{F}$ & 1,55 & 1,42 & 1,37 & 1,38 & 1,38 & 1,36 & $1,41 \mathrm{~A}$ \\
\hline
\end{tabular}

Médias seguidas por letras distintas na coluna, dentro de cada variável, diferem entre si pelo teste Fisher $(\mathrm{P}<0,05)$ *Efeito quadrático significativo dos níveis de metionina + cistina da dieta.

\section{CONCLUSÕES}

Os níveis de metionina + cistina que propiciam maior ganho de peso de codornas de corte EV2 em crescimento são $0,95 \%$ na fase inicial $\left(7^{\circ}\right.$ ao $21^{\circ}$ dia) e $1,03 \%$ na fase total $\left(7^{\circ}\right.$ ao $42^{\circ}$ dia de idade), o que corresponde às relações de metionina + cistina: lisina de 0,73 e $0,79 \%$, e ao consumo de metionina + cistina diário de $0,134 \mathrm{~g}$ e $0,234 \mathrm{~g} /$ codorna, respectivamente.

\section{AGRADECIMENTOS}

Ao Conselho Nacional de Desenvolvimento Científico e Tecnológico - CNPq, pelo financiamento do projeto.

\section{REFERÊNCIAS BIBLIOGRÁFICAS}

BAKER, D.H.; HAN, Y. Ideal amino acid profile for chicks during the first three weeks posthatching. Poult. Sci., v.73, p.1441-1447, 1994.

BARBOSA, M.J.B.; JUNQUEIRA, O.M.; ANDREOTTI, M.O. et al. Desempenho e rendimento de carcaça de frangos de corte submetidos a diferentes níveis de treonina e lisina, na fase final de criação. Rev. Bras. Zootec., v.30, p.1476-1480, 2001.

CORRÊA, G.S.S.; SILVA, M.A.; FONTES, D.O. et al. Efeito de diferentes níveis de proteína e energia sobre o rendimento de carcaça de codornas europeias. Arq. Bras. Med. Vet. Zootec., v.57, p.266-271, 2005. 
CORRÊA, G.S.S.; SILVA, M.A.; CORRÊA, A.B. et al. Exigência de metionina + cistina para codornas de corte em crescimento. Arq. Bras. Med. Vet. Zootec., v.58, p.414-420, 2006.

CORRÊA, G.S.S.; SILVA, M.A.; CORRÊA, A.B. et al. Exigência de proteína bruta e energia metabolizável em codornas de corte durante a fase de crescimento. Arq. Bras. Med. Vet. Zootec., v.59, p.488-494, 2007a.

CORRÊA, G.S.S.; SILVA, M.A.; CORRÊA, A.B. et al. Exigência de proteína bruta e energia metabolizável para codornas de corte EV1. Arq. Bras. Med. Vet.Zootec., v.59, p.797-804, 2007b.

CORRÊA, G.S.S.; SILVA, M.A.; CORRÊA, A.B. et al. Exigência de proteína bruta para codornas de corte EV1 em crescimento. Arq. Bras. Med. Vet. Zootec., v.59, p.1278-1286, 2007c.

JENSEN, L.S. Exceso de grasa. Um problema para la industria del pollo de engorda. Avic. Profiss., v.5, p.15-16, 1987.

MORAN Jr., E.T. Response of broiler strain differing in body fat to inadequate methionine: live performance and processing yields. Poult. Sci., v.73, p.1116-1126, 1994.

MURAKAMI, A.E.; FURLAN, A.C.; TATEISHI, A. et al. Exigência de metionina para codornas japonesas (Coturnix coturnix japonica) em postura. In: REUNIÃO ANUAL DA SOCIEDADE BRASILEIRA DE ZOOTECNIA, 31., 1994, Maringá. Anais... Maringá: SBZ, 1994. p.64.
NUTRIENT requirements of poultry. 9.ed. Washington: National Academy of Sciences, 1994. p.44-45.

PINTO, R.; FERREIRA, A.S.; DONZELE, J.L. et al. Exigência de metionina mais cistina para codornas Japonesas em crescimento. Rev. Bras. Zootec., v.32, p.1174-1181, 2003.

SCHUTTE, J.B.; PACK, M. Effects of dietary sulphur containing amino acids on performance and breast meat deposition of broilers chicks during the growing and finishing phases. $\mathrm{Br}$. Poult. Sci., v.36, p.747-762, 1995.

SISTEMA para análises estatísticas - SAEG. Versão 9.0. Viçosa: UFV, 2007.

STRINGHINI, J.H.; CAFÉ, M.B.; MOGYCA, N.S. et al. Níveis de energia metabolizável e metionina para codornas japonesas em postura (Coturnix coturnix japonica). In: CONFERÊNCIA APINCO DE CIÊNCIA E TECNOLOGIA AVÍCOLA, 1995, Campinas. Anais... Campinas: FACTA, 1995. p.125-126.

TORRES, R.A.; CORRÊA, G.S.S.; SILVA, M.A. et al. Desempenho de codornas EV2 para corte alimentadas com dietas com diferentes níveis de metionina + cistina durante a fase inicial. In: REUNIÃO ANUAL DA SOCIEDADE BRASILEIRA DE ZOOTECNIA, 2005. Goiânia. Anais... Goiânia, GO: SBZ, 2005. 